\title{
Effect of processing factors on the characteristics of centrifugal casting
}

\author{
Shubhashree Mohapatra ${ }^{1}$, Hrushikesh Sarangi ${ }^{1, *}$, and Upendra Kumar Mohanty ${ }^{1}$ \\ ${ }^{1}$ Department of Mechanical Engg., ITER, SOA Deemed to be University, Bhubaneswar 751030, Odisha, India
}

Received: 22 May 2020 / Accepted: 28 July 2020

\begin{abstract}
Centrifugal castings are produced by pouring liquid metal into rotating moulds. It solidifies under the influence of centrifugal forces, directed from the center to the periphery of the mould on account of mould rotation, and exhibits directionality in solidification which helps to eliminate voids and discontinuities in the resultant casting, usually encountered in gravity castings. Also, a compositional gradient is sat up in the melt which can be monitored, to produce functionally graded materials (FGMs) of choice with multi-functionality. The pouring rate, pouring temperature, mould temperature, and mould material can be suitably selected and altered in isolation or in combination, to generate a desired thermal gradient in the melt which decides its cooling rate. The cooling rate of the melt has the greatest impact on the grain structure of the casting. On the other hand, the grain structure of the casting governs its mechanical performance and decides the suitability for any specific end-use. Thus, different processing factors influence the characteristics of centrifugal casting. In the present article, a sincere attempt is made to analyze the effect of these factors and to enumerate the role played by each one of these factors in deciding the centrifugal casting characteristics.
\end{abstract}

Keywords: Graded distribution / functionally graded materials / reinforcement phase / rotating mould / directionality in solidification / micro-structural refinement

\section{Introduction}

High standards of soundness of the casting, resulting from feeding under the influence of centrifugal force, constitute the chief characteristic of centrifugal casting method. Grain size refinement and distribution/segregation of the inclusions/second phase/rejected solute atoms in the matrix also frame important characteristics of castings produced in rotating moulds. These characteristics decide the specific end-use of the centrifugal casting. The grainstructures, mechanical property enhancement, graded distribution of the second phase/inclusion etc. can all be tailored by manipulating various mould factors and processing factors associated with the production technique. The process is effectively used for production of Functionally graded materials (FGMs) which include different functionally graded metal matrix composites (FGMMCs) [1-14]. Aluminium and aluminium matrix FGMMcs reinforced with hard SiCp particles [15-22] can be cited as an examples. The graded properties of these FGMMCs, such as surface hardness and wear resistance

\footnotetext{
* e-mail: hrushikeshsarangi@soa.ac.in
}

could be furthered by adopting heat treatment methods. The advantages of FGMMC includes gradation of mechanical properties throughout the casting which can impart high temperature wear resistance at surface, increase in fracture toughness and reducing the crack propagation, reducing interfacial stresses etc. other properties includes reduction of interfacial and thermal stresses and increase of adhesion at metal-ceramic interface [23,24].

Luan et al. [25] adopted centrifugal casting methods successfully for refining of eutectic carbides in high speed steel (HSS) rolls for enhancement of mechanical properties. Niu et al. [26] adopted an in-situ synthesis method to provide a WC coating on grey cast iron, in the centrifugal casting route. The coated surface exhibited increased surface hardness values compared to the uncoated surface.

On account of the soundness of the product, the centrifugal casting technique finds its use in fabrication of various machine components like gear blanks, impellers, wheels, brackets, rotors, etc. [27]. Centrifugal casting methods are also adopted for fabrication of nano wires using Lead-Bismuth (Pb-Bi) eutectic alloy [28] at a very high rotational speed of the mould (around 17,000 rpm). The nano-wire is formed inside anodic aluminium oxide 
(AAO) templates. The method is also adopted for the development of reactor fuels [29-31], production of steel lined composite tubes [32,33], centrifugal slip casting of zirconia [34], etc. The list is unending and covers a vast range of products establishing the importance and versatility of the process in manufacturing technology. Thus, it is only pertinent to have a greater insight to the processing details of centrifugal casting methods and analyze the different mould and processing factors involved for a clear understanding, evaluation and control over the process.

Despite continued efforts researchers have not been able to frame general rules to co-relate mould rotation and the resultant casting structure as influenced by the mould and processing factors such as, mould dimensions, mould rotational axis, mould materials, mould pre-heat temperature, speed of rotation of the mould, solidification rate, pouring temperature and composition of the liquid metal. This is because of the interaction of several mechanisms involved, pertaining to mould vibrations, probable fragmentation of the dendrule-tips in the rotating moulds, nonuniform temperature drops in different portions of the liquid metal during solidification, etc. However, it is heartening to note, Chang, et al. [35] used a modified cellular automation model [36] to study and simulate the influence of different mould factors and processing parameters on the grain-size and its distribution in the centrifugal casting. The researchers report, in a vertical axis-mould, formation of equiaxed grains is favored at a moderate speed of rotation of the mould, lower extents of super-heat in the liquid metal, relatively low mould pre-heat temperatures and slightly high concentrations of solute in the liquid metal. The above reflects on the simultaneous effect of several mould and processing parameters on the characteristics of centrifugal casting.

Solidification rate of the casting influences its grain structure and the structure related properties. The solidification rate can be altered suitably by the use of moulds fabricated from different materials, heating the mould to different pre-heat temperatures and adopting different pouring temperatures. In some cases, mould cooling arrangements may also be employed to set up a desirable thermal gradient to achieve the most desired solidification rate. In the casting of HSS rolls in centrifugal casting route, in particular, an increased solidification rate is adopted by suitably adjusting the above mentioned parameters so that the eutectic carbide grains are rendered fine and get uniformly distributed in the matrix [25] with the resultant advancement of its wear resistance and thermal fatigue properties.

The influence of flow pattern of the liquid metal in a horizontal rotating mould on the casting characteristics was numerically simulated and cold-modeled by Keerthiprasad et al. [37]. In this case, the injection angle and the position of insertion of the chute into the mould, were considered as factors for deciding the mould filling [38]. The investigators also considered different processing variables, such as the viscosity of the liquid metal, mould size, rotational speed of the mould, etc. for their investigation. It was reported, the numerical simulation results and cold modeling results pertaining to different fluids in terms of their flow pattern, agreed considerably. The above established that the flow pattern of the liquid metal in a rotating mould could be numerically simulated to ascertain its influence on casting characteristics.

The method of pouring also influences the centrifugal casting characteristics. Sarkar et al. [39] reported, bottom pouring in vertical mould for centrifugal casting, accounts for a stable filling process for the mould compared to toppouring. This is because, in bottom-pouring any crashing between the metal being poured from the top and the column of rising liquid metal from the bottom, are avoided. $\mathrm{Wu}$ et al. [40] also reported that bottom pouring gives the stable filling compared to top pouring with minimum defects, during vertical centrifugal casting. However, top pouring system is beneficial for rapid filling of the mould with the cost of melt spattering, gas entrapment and inclusion defect [41].

The above would suggest centrifugal casting techniques constitute specialized production techniques and could be tailored to best suit the end-use of the product by monitoring the associated factors concerning the mould and the process. To have a better understanding and control of these factors it is mandatory to analyze these at length so that the full advantage of the method could be made available. The present article is a sincere effort towards this end.

\section{Processing factors in centrifugal casting production}

\subsection{Rotational speed of the mould}

The rotation per minute ( $\mathrm{rpm}$ ) of the mould is selected, keeping an eye to the extent of the centrifugal force to be generated. Though, there are no generalized criteria for deciding the extent of centrifugal force, for a horizontal axis casting, the speed of rotation of the mould should be high enough to prevent raining of the liquid metal when it occupies the upper-half of the circular rotating mould. Also, the centrifugal force developed should be enough to take care of the slip between the liquid metal and the rotating mould wall. The rpm of the mould can be obtained from Nomograms depicting relationship between diameter of the mould and rpm of the mould for generating the required centrifugal force. ' $\mathrm{N}$ ' is given as for horizontal moulds,

$$
N=42.2\left(\frac{G_{\text {factor }}}{D}\right)^{\frac{1}{2}}
$$

for vertical moulds,

$$
N=42.2\left(\frac{L}{r_{t}^{2}-r_{b}^{2}}\right)^{\frac{1}{2}}
$$

where $G$ factor $=\frac{F_{c}}{F_{g}},\left(F_{c}\right)$ is the centrifugal force and $\left(F_{g}\right)$ is the gravitational force.

' $D$ ' is the diameter of the mould in meters. ' $L$ ' is the length of the mould axis in meters. ' $r_{t}$ ' and ' $r_{b}$ ' are the radius 
at the top and bottom in meters respectively, of the parabolic bore formed on the liquid metal on account of mould rotation.

' $N$ ', the rpm of the mould, can be varied suitably to alter the ' $G$ ' factor so that the desired centrifugal force can be generated.

\subsubsection{Mould rotational speed and metal flow in the mould}

The rotational motion of the mould sets in metal flow in the mould during solidification. It decides the characteristics of the centrifugal casting. The grain structures, segregation/ distribution of the un-dissolved phases and the suspended crystals in the melt, casting soundness and formation of any specific microstructure, are all influenced by the metal flow in the mould. Thus, it is advisable to have a visual flow characteristic assessment of the liquid metal in a rotating mould. However, the opaque mould and the opaque liquid metal create barriers in such assessments. Never-the-less, several investigators [37,42-47] have studied the flow behavior of a liquid in a rotating cylinder using different fluids with different viscosities, attempting a cold-modeling of centrifugal casting. A computerized simulation of the flow field described by the liquid metal in a rotating mould has been carried out by these investigators. The coldmodeling and simulation results are seen to be in good agreement explaining the real-life situation qualitatively, in terms of the microstructure and segregation issues in the casting [37].

Mukunda et al. [48,49] provided an explanation for the movement of the liquid metal in a rotating mould right from the teeming to the solidification stages. The viscosity of the metal is the lowest at teeming, the teeming temperature being the highest in the entire process of the metal feed, metal-flow and metal-solidification. The liquid metal poured into the mould spreads on the inner mould wall due to its low viscosity and the frictional drag of the inner wall. A thin layer of the liquid metal is, thus, formed on the inside surface of the mould wall. The rest of the liquid metal is directed away from the centre of the mould. The investigators report, at a critical/optimum speed of rotation, depending on the size of the mould and viscosity and volume of the liquid metal involved, all of the liquid metal is picked-up by the rotating mould wall. It sticks firmly on the inside mould surface and forms a specific thickness of the metal which subsequently solidifies forming the mould tube of the given specific wall thickness. Rao et al. $[50,51]$ opine, the critical speed is also a function of the composition of the liquid metal. The above provides, under specific conditions of mould size, viscosity of the liquid metal, volume of the metal required for a specific thickness of the product and composition of the metal the speed of rotation of the mould must exceed the critical speed. Below the critical speed all of the liquid metal is not picked up, shows instability and forms castings with a poor irregular surface [49]. At speeds above the critical speed hot tears may be formed on the casting surface. It is claimed [48], centrifugal castings formed with appropriate considerations pertaining to the critical speed exhibit good mechanical properties and have a lower wear rate. The correct selection of the speed of rotation forms an important criterion in the production of centrifugal castings, the rotational speed of the mould having a direct say on the flow speed of the liquid metal in the mould in both longitudinal and circumferential directions. Park et al. [52] report, when the rpm of the mould is increased from 1200 to 2500 , the flow speed of the metal is almost doubled. The situation is worsened when the melt being longitudinally fed and the melt being reflected from the mould wall in a horizontal mould, collide. Here a turbulent flow pattern is generated. In this event if the metal considered is a reactive metal like Aluminium, the turbulent flow is certain to enhance oxidation of the metal and encourage the formation of porosity in the casting affecting its compactness. Flow pattern of the melt in the mould as influenced by the rotational speed of the mould control the grain-structure of the casting and governs its structure oriented properties. However, rpm of the mould is not the only contributing factor in this respect. Size of the mould, pouring temperature, speed of pouring, mould preheat temperature, thermal gradient that dictate the solidification rate, the melt viscosity dependant on the melt composition, etc. also influence the flow pattern of the melt in the mould. On this count, the issue of developing any specific structure in the centrifugal casting, is complicated. Also, any attempt at assessing the contribution of any of the factors independent of the others towards this end, is futile.

Chang et al. [35], simulated the microstructure of cast $\mathrm{Al}$ alloys using a modified cellular automation method (MCA) [36]. Their simulation results, presented in Figure 1 throw ample light on the mechanism of formation of the grain-structure in the Al casting. At 'zero' speed (Fig. 1a), i.e, in a static mould, the grain structure consisted of a chill zone with fine equiaxed grain structure adjacent to the inner surface of the mould. A columnar zone coming out from this chill-zone and a zone consisting of equiaxed grains at the centre of the casting, could also be evidenced. At lower rotational speeds of the mould (say $50 \mathrm{rpm}$ ) (Fig. 1b), a slight alteration in the distribution of nuclei could be seen in the melt. The equiaxed grains at the centre of the casting were seen to have slightly enlarged and the columnar zone became slightly narrower compared to the previous case. With further increase of the rotational speed to $100 \mathrm{rpm}$, a transition from equiaxed to columnar grain structure in the microstructure could be observed. This second columnar zone broadened and the zone of equiaxed grains did not show up at the centre as the mould rpm was increased as presented in Figure 1c-e. This is because, on account of the rotation of the mould the vibrations in the melt disturbed the accumulation of the solute atoms ahead of the primary columnar grains resulting in the elimination of the effects of the constitutional undercooling. It may be noted, if not disturbed by mould vibrations, the undercooling could have favored the formation of an equiaxed zone. Thus, the equiaxed grains formed in the initial stages of solidification, at lower rpms of the mould, did not showup in the latter stages, at higher rpms of the mould under the influence of higher extents of centrifugal force and the accompanying mould vibrations. It was also seen, as zone of columnar grains became narrower with the increase of mould rotational speed, the equiaxed grains were rendered finer. 


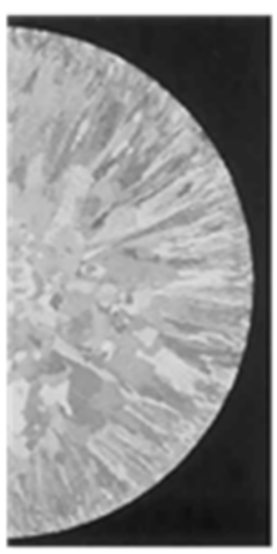

(a)

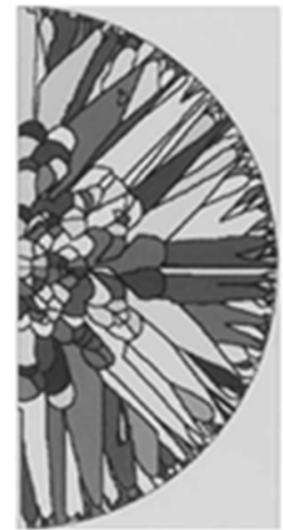

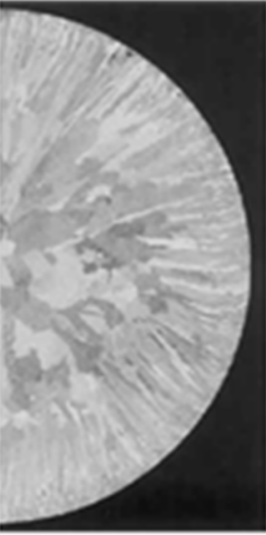

(b)

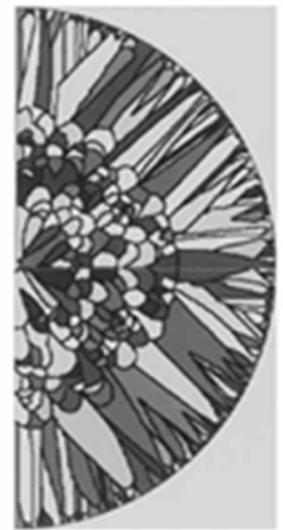

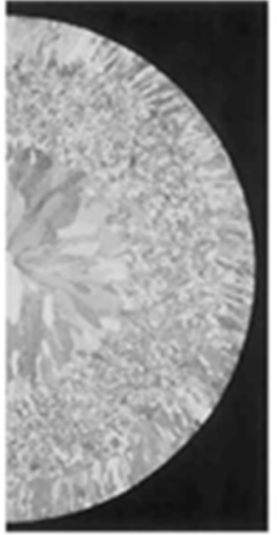

(c)

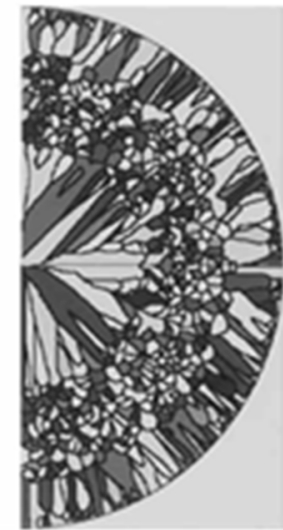

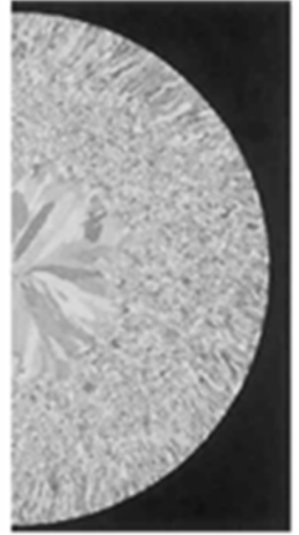

(d)

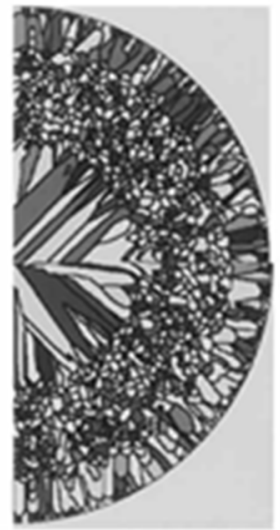

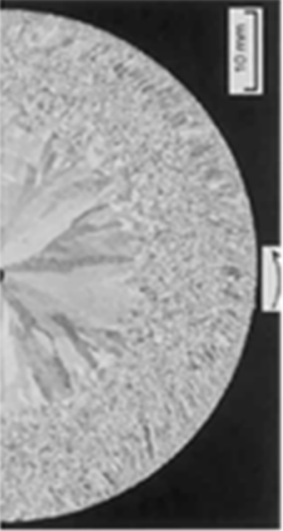

(e)

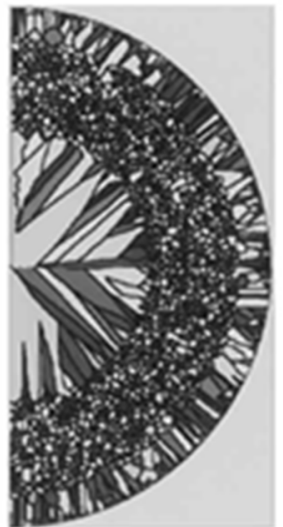

Fig. 1. Simulated and experimental macrostructures of an Al-1.0mass\%Si alloy with various mould velocities in centrifugal casting: (a) $0 \mathrm{rpm}$, (b) $50 \mathrm{rpm}$, (c) $100 \mathrm{rpm}$, (d) $200 \mathrm{rpm}$, and (e) $400 \mathrm{rpm}$ [35].

It could clearly be seen, under the influence of the rotational motion of the mould, the columnar grains tended to get inclined in the direction of mould rotation. This tendency could be attributed to considerable flow of the melt in the circumferential directions [53]. The authors [35] validated their simulation results with extensive experimentation conducted under varied conditions of the mould rpm, solute concentration, mould preheat temperature, etc. The speed of rotation of the mould decides the rate of transport of hot metal from the centre to the peripheral regions of the mould on account of the resultant centrifugal force. It, thus, affects the heat transfer in the mould and can be manipulated to establish the desired temperature gradient and the concurrent rate of cooling/ solidification of the metal. As shown in Figures 2 and 3 , the altered thermal gradient and cooling rate changes the extent of the solid/liquid (mushy) zone in the casting. An enhanced rate of cooling and a stiffer thermal gradient lessens the extent of the mushy zone and reduces the micro shrinkages. Under these condition a more compact, sound casting results, nucleation rate being higher than the rate of growth giving rise to a finer grain structure. Factors like initial temperature of the mould, pouring temperature and pouring speed of the liquid metal, any adopted external means of cooling of the mould etc. can also be manipulated along with alterations of mould rotational speed to affect grain refinement and soundness of the casting.

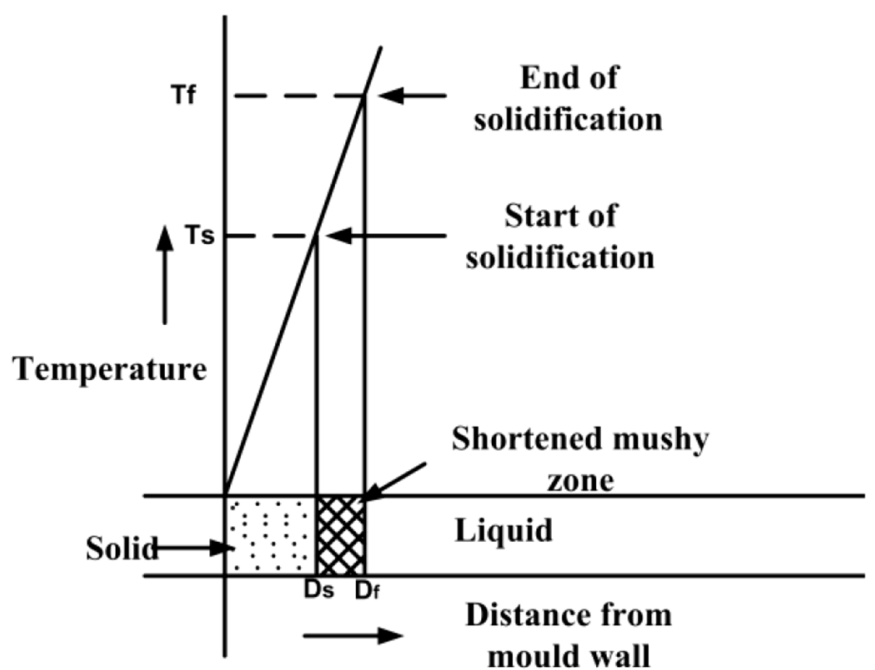

Fig. 2. Showing the narrow mushy zone by a stiff temperature gradient.

The overall picture due to the rotation of the casting alloy along with the rotating mould is some what complex on account of the relative motion of the liquid metal by a process of slip when the rotation of the mould 


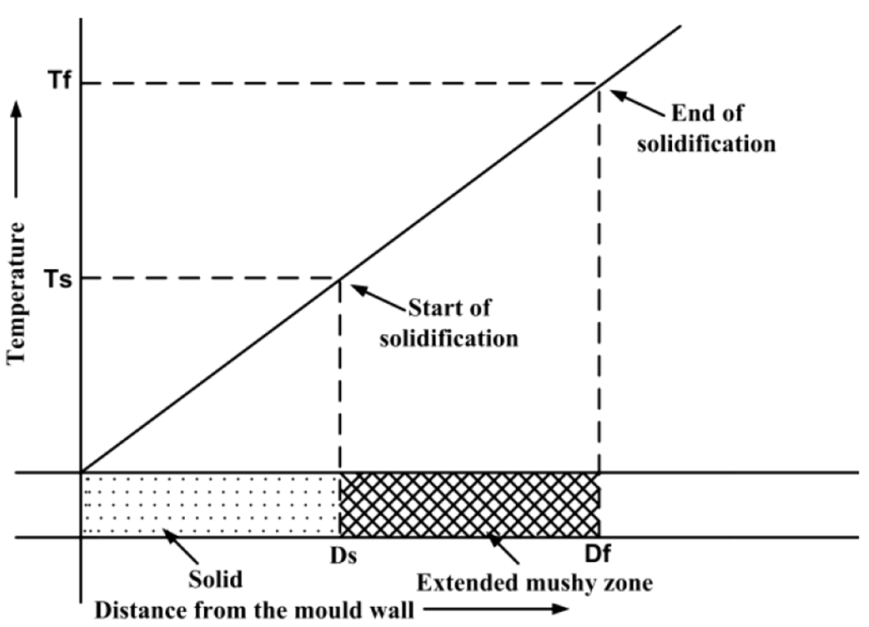

Fig. 3. Showing the extended mushy zone by a shallow temperature gradient.

is accelerated. On the other hand, the vibration caused in the liquid metal and the fragmentation of the tips of the dendritic arm may help the nucleation of the equiaxed grains. The disturbances and vibrations may also eventually disturb the barrier offered by the solute rich liquid at the interface caused by the rejection of solute atoms from within the melt. This may lead to the tendency of columnar growth in the casting, in certain cases.

On the one hand, an increased rotational speed, most commonly, increases grain refinement. On the other hand, the vibrations and disturbances in the melt at low rotational speeds of the mould cause fragmentation of the tips of the growing dendrules. These fragments transported to favorites sites in the melt grow into fine equiaxed grains. As a consequence, the turbulence created by the instability resulting from the vibrating melt at low rotational speeds of the mould, may also cause grain refinement.

\subsubsection{Mould rotational speed and banding microstructure}

The speed of rotation of the mould promotes formation of 'banding' microstructure [54] that pertains to a structural irregularity. Banding microstructure manifests itself in concentric zones of dissimilar microstructure due to segregation of alloy constituents including impurities in the melt. The banding microstructure is more noticeable in larger castings, more specifically in horizontally cast thick walled cylinders. Yeh et al. [55] have presented the banding microstructure schematically (Fig. 4). The mechanism of 'banding' lies in the variation of the cooling rates in the casting thickness due to liquid mobility as a consequence of the resultant centrifugal force. Since the centrifugal force generated is insignificant for small castings, which is not sufficient for 'banding', banding does not show up in small centrifugal castings. Thus, in small centrifugal castings in place of a banding microstructure a finer and more uniform structure may be encountered.

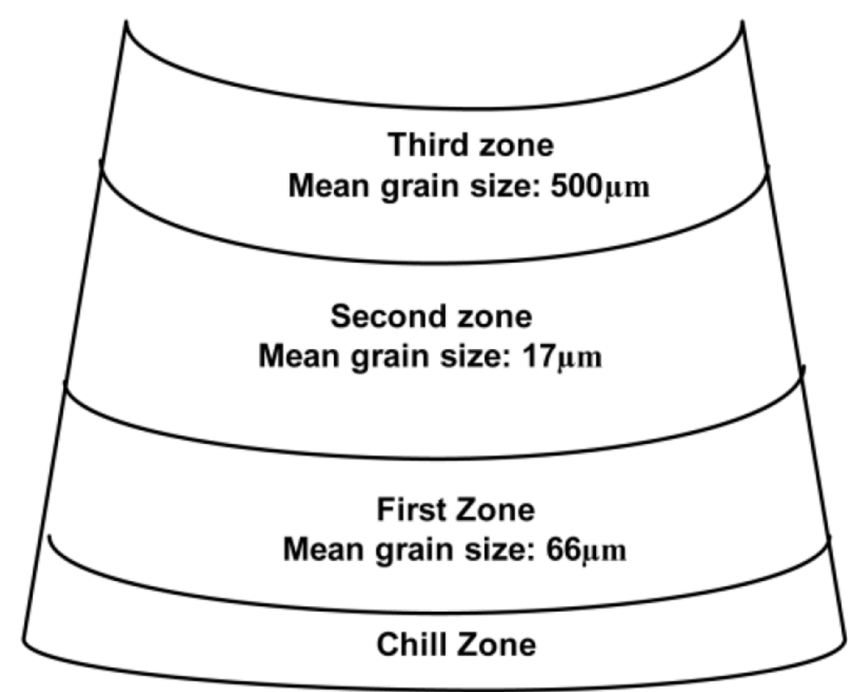

Fig. 4. Schematic illustration of the 'banding' microstructure [55].

\subsubsection{Mould rotational speed and segregation/distribution of un-dissolved, suspended crystals}

Under the influence of the centrifugal force in a rotating mould, the un-dissolved, suspended particles in the liquid metal experience a motion in relation to the liquid in which these are contained. In general, the denser particles are transported to the peripheral region while the constituents with lesser densities tend to get segregated to the central portion of the melt. However, the centrifugal segregation of the constituents in the liquid metal can occurs in either of the directions. In certain specific cases, when differential freezing causes rejection of heavier solute elements, these may get transported to the central portions of the casting, being contained in the melt just ahead of the solidification front moving inwards from the peripheral region of the mould. Once the initial faster rates of cooling at the outer surface gives in to a slower cooling rate, the solid/liquid interface moves inwards slowly and retains the moving particles, thus, causing the segregation of these particles, allowing these to move to the inner surface continuously. Thus, density of the constituents may not be the only deciding factor for segregation of the un-dissolved, suspended crystals in the melt.

The mode of freezing of the melt in a rotating mould decides the mode of segregation in the resultant casting. For an instance, segregation would take place when a low melting point liquid at advanced stages of solidification, would solidify, acquire higher density and get transported outwards to the peripheral regions as a consequence of mould rotation. Also, in specific cases, when the alloy concerned provides for dispersed crystallization, relative movements may be caused between solid and liquid in the same melt resulting in the transport of the denser crystals to the peripheral regions leaving the less dense crystals to occupy the central portions. In addition to the rpm of the mould, processing factors like pouring temperature, pouring speed, cooling rate, etc., which influence the freezing 
of the casting by setting in a desired thermal gradient, also participate in deciding the mode of segregation/distribution of the suspended crystals in the melt.

Assuming constant rotational speed and neglecting the growth of the particle during solidification, the position of the particle in the melt at any instant of time ' $t$ ', can be given as:

$$
r=r^{*} e^{A \omega^{2} t}
$$

where $r^{*}$ is the initial location of the particle in the melt; ' $r$ ' is the location of the particle at time ' $t$ '; ' $\omega$ ' is the constant angular velocity of rotation of the mould and ' $A$ ' is a function of the viscosity of the melt $[56,57]$.

Viscosity of the melt increases with drop of temperature and with the volume of the rejected solute particles from within the melt. Since different volume fractions of the solute particles are rejected at different temperatures, the speed of movement of solute particle varies at different temperatures.

Two essential conditions of macro segregation of phases in the melt are, relative motion of the solid-liquid phases in the mushy zone and rejection of solute particles from within the melt at the solid-liquid interface. The relative motion between the solid-liquid phases, however, is caused due to the movement of the liquid in the solid-liquid region. The liquid movement, on the other hand, is caused due to the contraction of the liquid under thermal fluctuations, volume shrinkages due to the formation of the solid phase and the resultant density differences in the interdendritic liquid [58]. Macro-segregation is 'normal' when the advancing solidification front pushes the solute-enriched liquid towards the hotter centre of the mould. 'Normal' macro-segregation is caused by convection currents due to the flow of the liquid driven by solid shrinkages. The macrosegregation is said to be 'reverse' when the solid enriched liquid is transported towards the casting peripheries. It is caused when capillary forces push the concerned liquid with higher solid concentrations through interdendritic channels in an opposite direction. Also, 'normal' macrosegregations occur in equiaxed grains where as 'reverse' macro-segregations occur in a columnar structure $[59,60]$ providing for interdendritic channels. The intersection of the two solidification fronts moving in opposite directions in the solidifying casting plays an important role concerning macro-segregation issues. One of the fronts moves from the casting periphery to the casting inner face due to heat conduction through the mould wall to the ambience. Radiation and forced convection, however, cause the second solidification front to move from the inner to the outer face of the casting. The intersection of these two moving fronts constitute the final solidification zone and decides macro-segregation in the inter dendritic liquid under the influence of thermal contraction and solidification shrinkages. Initial mould temperature, pouring temperature, rate of cooling, rate of pouring of hot metal, etc., can be varied to alter the rate of movement of these two fronts, thus, deciding the location of intersection of these fronts in the solidifying melt. The macro-segregation can be relegated to the inner, outer or central portions of the casting by decisively deciding the location of this intersection.

An advanced, elaborate centrifugal casting process can accentuate a graded distribution of the reinforcement particles in a matrix of choice to help fabricate FGMs with multi functionality. For an example, in the processing of Al-Mg2Si the lighter Mg2Si reinforcement get segregated in the bore region. These hard Mg2Si particles impart good wear resistance to the inner casting surface. However, when improved wear properties are needed on the surface of the casting, the reinforcement particles chosen are heavier than the Al matrix. Examples are Al-SiC [61], Al-Al3Ni [62], Al-Al3Ti [63]. In this case, the concentration of hard, heavy, particulate material, is high at the surface. The surface develops good wear properties. Also, the concentration of such particles is lowered gradually away from the surface with the development of good strength and ductility properties in this region.

\subsection{Pouring temperature and pouring rate of hot metal}

2.2.1 Pouring temperature, pouring speed and the cast grain-structure

Rate of cooling and desired thermal gradient to influence the solidification rate are dependent on the pouring temperature and pouring rate of the hot metal. Pouring temperature has a definite say on the solidification pattern of the casting. A lower pouring temperature reduces the solidification time and causes grain refinement. The resultant grain structure consists of equiaxed grains. However, a higher pouring temperature enhances the time of solidification. Here, the nuclei are at temperature for a longer time and the grain structure consists of columnar grains. Mould filling can be satisfactory for a casting with high surface area-volume ratio, when the pouring temperature is high. In this case heat is lost from the casting at a higher rate. On the other hand, a heavy and compact casting would need a lower pouring temperature for satisfactory mould-filling. Slow pouring rate promotes directional solidification. Also, it is advantageous as surface tearing on the casting can be avoided with a slow pouring rate under which the full centrifugal force is developed gradually on the solidifying skin of the casting. However, an optimal pouring rate has to be employed for the completion of the process of casting before the liquid metal becomes sluggish and mould filling suffers.

The ability of temperature of pouring for grain refinement is greater in centrifugal casting as compared to castings produced in static moulds. This is because of the vibrations and turbulence caused in rotating moulds. In a turbulent, solidifying melt, the tips of the dendrites get fragmented. These are carried to the relatively hot central regions of the melt where many of the fragmented tips disappear under the influence of the heat. However, some of the fragmented tips may reach favorable regions and are rendered stable resulting in crystal multiplications, ultimately resulting in grain refinement. The data pertaining to grain refinement as a consequence of lowering of the pouring temperature by lowering the superheat (pouring temperature $=$ melting temperature + superheat) 
Table 1. Correlation of superheat temperature and grain size for IN-713LC super alloy [64].

\begin{tabular}{ll}
\hline & Grain size $(\mu \mathrm{m})$ \\
\hline$p+150{ }^{\circ} \mathrm{C}^{a}$ & 3000 \\
$p+60{ }^{\circ} \mathrm{C}^{a}$ & 90 \\
$p+20^{\circ} \mathrm{C}^{a}$ & 65 \\
Centrifugal casting & 25 \\
\hline
\end{tabular}

${ }^{\text {a }}$ Pouring temperature $\left(P=1321{ }^{\circ} \mathrm{C}\right.$, melting point of IN-713LC super alloy).

are presented in Table 1 [64] and relates to castings of IN-713LC super alloy. Clearly, with a drop of super heat by $20{ }^{\circ} \mathrm{C}$ the grain size is seen to drop to $65 \mu \mathrm{m}$. On the other hand with the adoption of centrifugal casting techniques, the grain size is seen to further drop to $25 \mu \mathrm{m}$. The researchers [64] report an increase in the yield strength and the room temperature tensile strength of the casting simultaneous to the process of grain refinement. However, when the grain size is reduced to $25 \mu \mathrm{m}$ a sharp drop in the ultimate strength and elongation, due to the initiation of an early fracture as a result of the presence of micro porosities associated with the ultra fine grain structure, is noticed.

The effect of pouring temperature on grain refinement and the consequential mechanical properties, have been assessed by Shailesh et al. [65], while casting $4600 \mathrm{Al}$ alloy in a rotating mould. The alloy finds its use in the defence, aerospace and the automobile sector. The experimenters used Taguchi method of design of experiments to optimize the process parameters and used ANOVA technique for analysis of their experimental data. The analysis revealed a coarsening of the grain structure with a relatively higher pouring temperature accompanied with a reduction in the mechanical properties. Also, with a lower pouring temperature of $720^{\circ} \mathrm{C}$ an enhancement of mechanical properties could be observed along with formation of fine grains. In the IN-713LC alloy centrifugal casting [64], however, grain refinement is accompanied by the fragmentation of carbides (Fig. 5) which enhances the ability of the cast structure to inhibit the slide of dislocations. As a result of the above, both the yield strength and the ultimate strength of the casting are seen to be increased [66-71]. Thus, grain refinement can be regarded as an effective method of upgrading materials [72-74] and can be accomplished by selecting an appropriate pouring temperature.

\subsubsection{Pouring temperature and segregation/distribution of second phase inclusions in the casting}

The centrifugal casting method is a simplified and cost effective method for the fabrication of various FGMs [75]. In FGMs there is a gradation of composition over the volume of the casting that brings about the corresponding gradation in the properties of the material [76]. The gradation of composition is primarily achieved due to the varied centrifugal forces imparted to the different solid particles (reinforcements) and the molten metal housing them, on the basis of the differences in the

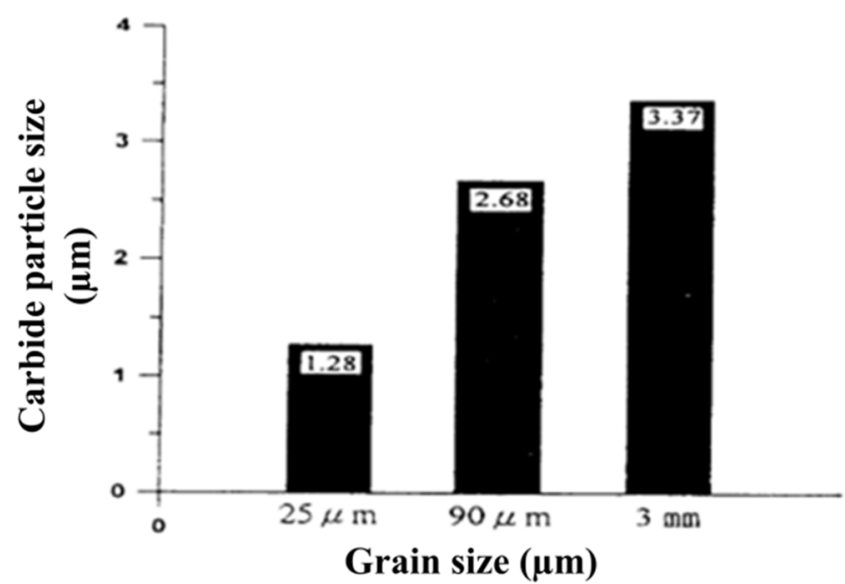

Fig. 5. Image analysis results of the carbide particle size in IN713LC super alloy with various grain size [64].

densities. These materials, thus, acquire different velocities and describe different distances in the melt, bringing in a gradual distribution/segregation of the solid particles in the melt. Such graded distribution imparts graded properties to the resultant casting.

Zhang et al. [77] formulated an equation to compute the centrifugal force imparted to the different solid particles contained in a metal melt. The centrifugal force on a solid particle of mass ' $\mathrm{m}$ ' is given as:

$$
\begin{aligned}
F & =m \omega^{2} r=\pi^{2} m N^{2} r / 900=0.011 m r N^{2} \\
& =0.011 \rho v r N^{2}
\end{aligned}
$$

where $F$ centrifugal force; $m$ the mass of the particles; $\omega$ the rotational angular velocity of the mould; $r$ the radius of rotation; $N$ number of revolution of the mould; $\rho$ the density of the particle; $v$ the velocity of the particle.

Young et al. [15] used this equation for an Al-19Si-5Mg alloy, to compute the centrifugal force acting on the constituents with different densities (Al-2.37, primary silicon-2.33 and Mg2Si-1.93). The velocities of the primary $\mathrm{Si}$ and Mg2Si particles in the Aluminium melt due to the different extents of centrifugal force experienced by the particles were estimated. It was found that the ratio of velocities of primary silicon particle to that of the Mg2Si particles were 13.9. Obviously, the concentration gradients of $\mathrm{Mg} 2 \mathrm{Si}$ and primary $\mathrm{Si}$ particles were set in the aluminium melt on the basis of this ratio which established the gradation of properties of the alloy. The distribution/ segregation in the alloy is very closely associated with the pouring temperature of the alloy. At a relatively high pouring temperature, the viscosity of the melt is low and solidification is continued over a longer period of time. The above allows the movement of the particles over a longer period, allowing for effective gradation of the constituent particles in the $\mathrm{Al}$ melt providing for gradation of properties. Also at the relatively higher temperatures of pouring the solidification rate, hence the rate of rejection of the solute atoms into the melt at the interface, is lowered. The rate of rise of viscosity of the melt is lowered on account of the lower volumes of solute rejection allowing 
free movement of the particles over a longer time, ensuring an effective gradation.

The influence of pouring temperature, preheat temperature of the mould and ' $\mathrm{G}$ ' factor $\left(G=\omega^{2} r / g\right.$; $\omega$-angular velocity; $r$-radius of the casting tube; g-acceleration due to gravity) on particle segregation were assessed by Raghunandan et al. [78]. The study pertained to fabrication of Al-Si-Mg FGM tube reinforced with insitu $\mathrm{Si} / \mathrm{Mg} 2 \mathrm{Si}$ particles, in the centrifugal casting route. The investigations revealed that the pouring temperature, mould preheat temperature and the $\mathrm{G}$ factor influenced the graded distribution of the 'Si', 'Mg2Si' reinforcement particles in the FGM tube. Also, it has been reported by several investigators [79-87] that the insitu reinforcement phase impart enhanced mechanical properties to the product concerned and that the pouring temperature and pouring rate of hot metal along with other processing parameters like the ' $G$ ' factor, influence the segregation of the insitu reinforcement particles in the cast product.

\subsubsection{Pouring temperature, pouring rate and some alloys of significance}

Pouring temperature and pouring rate affect the characteristics of centrifugal castings of different alloys of significance. The pouring temperature decides the rate of cooling of the melt in the centrifugal mould. Assisted by the preheat temperature of the mould, adopted mould cooling system, (if any) and the ' $G$ ' factor which is a function of the rotational speed of the mould, it decides the time at temperature of the melt. The above significantly affects the cooling rate deciding the time at temperature of the melt. This is bound to have an important say on the grain structure and the related mechanical properties of the casting.

\subsubsection{Macro segregation of $A /$ in $Z A-27$ alloy}

ZA-27 alloy is a zinc and aluminium die casting alloy having about 27 percent of aluminium. The alloy has good wear resistance and high strength properties. It also has good tensile and yield strength, good corrosion resistance, hardness, light weight, good bearing and creep properties. The alloy is also used for casting of cylinder liners, rings and bushings.

The alloy exhibits extensive macro segregation of aluminium when cast in the ordinary gravity casting route due to the difference in densities of $\mathrm{Al}$ and $\mathrm{Zn}[88,89]$. The segregation problem only gets aggravated when centrifugal casting methods are adopted due to the role of centrifugal forces [90], even when casting under the influence of optimum processing conditions. The lighter $\mathrm{Al}$ rich ' $\alpha$ ' phase always floats in the melt, occupies the casting inside surface relegating the $\mathrm{Zn}$ rich, heavier eutectic phase to the exterior surface of the casting. This leads to an aluminium rich inner surface due to the abundance of $\mathrm{Al}$ in the ' $\alpha$ ' phase resulting in the macro-segregation of Al to the inner surface. The extent of Al macro segregation, however, can be lowered by lowering both, the pouring temperature and the pouring rate. In this case lower extents of the $\mathrm{Al}$ rich ' $\alpha$ ' phase can float and get pushed to the inner casting surface, thus, decreasing the macro segregation of aluminium. However, the final solution to the macro segregation of $\mathrm{Al}$ can be reached by the addition of $\mathrm{Mn}$ to the Zn-A27 alloy since neither the pouring temperature nor the pouring rate could be lowered beyond a certain limit. The resultant, high temperature $\mathrm{MnAl}_{6}$ [91] phase can decrease the active sites of $\mathrm{Al}$ rich ' $\alpha$ ' phase nucleation, lessening the extents of migration of the Al rich phase in the melt. This can make the centrifugal casting of Zn-A27 alloy, viable.

\subsubsection{Melt-mould interfacial reactions in Ti-Al alloys}

The Ti-Al alloy (Ti-40\%, Al-47.5\%, V-2.5\%, and $\mathrm{Cr}-1 \%$ ) under consideration, is categorized as a high performance material. It has low density and good inherent mechanical properties at both low and high temperatures [92,93] and suitable for use in both aerospace and automobile industries. It is claimed [94], centrifugal casting methods are best suited for casting of this alloy. The alloy cast in the centrifugal casting route exhibits reduction of shrinkages, inclusions and minimum casting defects with an improvement in the structure development $[95,96]$. However, the interfacial melt-mould reaction during its centrifugal casting constitutes an important fabrication concern [94]. There is a possibility of cracking and low stability of the mould which renders the mould brittle when the casting operation is carried out at high temperatures. Thus, casting temperature, i.e, the pouring temperature, constitutes one of the most important factors for governing the mould-melt interface reactions. In order to have a greater insight into the interfacial reactions, Yanwei et al. [94] employed a Zirconia (ZrO2) mould with a surface coating that mostly contained Yttrium $\left(71 \% \mathrm{Y}_{2} \mathrm{O}_{3}\right)$. The pouring temperature was maintained at $1600^{\circ} \mathrm{C}, 1650^{\circ} \mathrm{C}$ and $1700^{\circ} \mathrm{C}$ respectively. Both $\mathrm{ZrO}_{2}$ and $\mathrm{Y}_{2} \mathrm{O}_{3}$ decomposed to the elemental $\mathrm{Y}, \mathrm{Zr}$ and ' $\mathrm{O}$ ' and the elements diffused into the mould substrate initiating chemical reactions with $\mathrm{Ti}$ and $\mathrm{Al}$ forming several new phases. With the rise of temperature more and more $\mathrm{ZrO} 2$ and $\mathrm{Y} 2 \mathrm{O} 3$ decomposed and the thickness of the interfacial reaction layer between the elements in the mould and the matrix at the interface increased. The freshly generated reaction products increased the hardness of the casting at the interface which gradually diminished from the interface to the inner substrate of the casting [97] and the possibility of cracking and low stability of the mould was lessened making centrifugal casting of the alloy a viable proposition.

\subsubsection{Centrifugal casting of 5500Al-Mg alloy}

The 5500 Al-Mg alloy is of significance owing to its suitability in several applications requiring light weight coupled with high strength. The alloy also possesses good corrosion resistance, high temperature mechanical properties and good wear resistance. Optimizing the process parameters by the use of Taguchi method of design of experiments, Shailesh et al. [98] studied the effect of different processing parameters on the mechanical characteristics of $5500 \mathrm{Al}-\mathrm{Mg}$ alloy. The process parameters included pouring temperature, mould pre-heat temperature, rotational speed of the mould etc. An augmentation of 


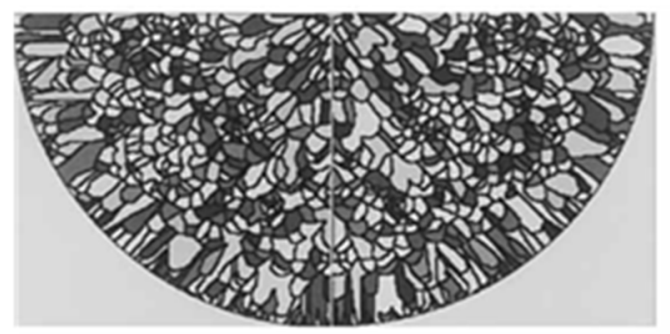

(a)
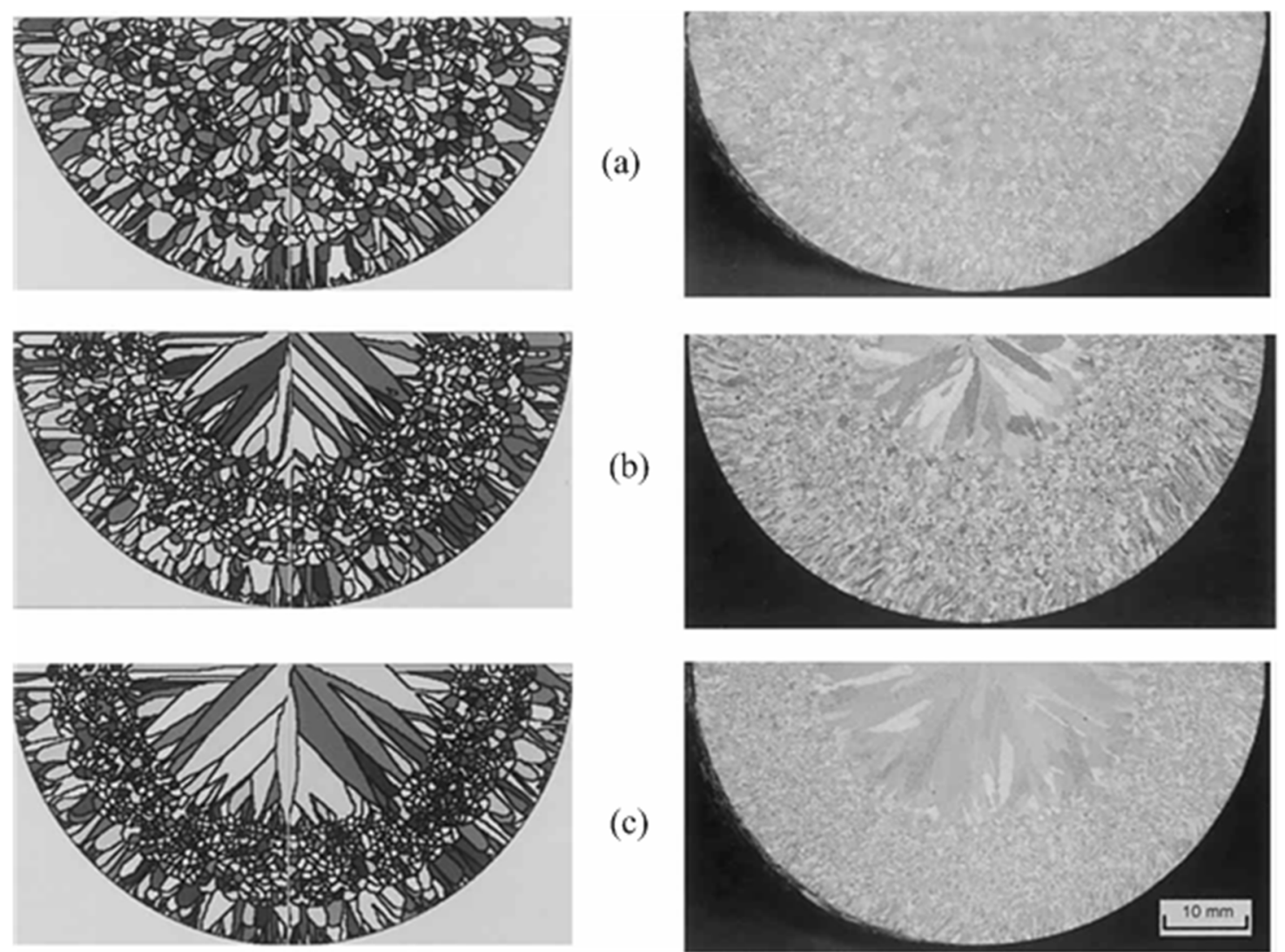

(b)

(c)

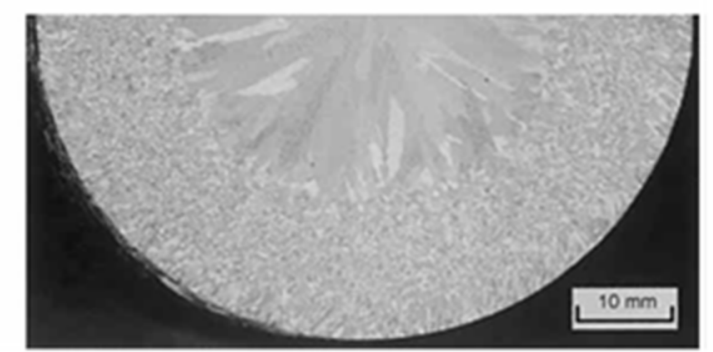

Fig. 6. Simulated and experimental macrostructures of an $\mathrm{Al}-1.0 \mathrm{mass} \% \mathrm{Si}$ alloy with a mould velocity of $200 \mathrm{rpm}$ and a pouring temperature of $760{ }^{\circ} \mathrm{C}$ for various mould preheat temperatures: (a) $10{ }^{\circ} \mathrm{C}$, (b) $70^{\circ} \mathrm{C}$, and (c) $150{ }^{\circ} \mathrm{C}[35]$.

mechanical properties could be evidenced when the pouring temperature was low. At a low pouring temperature the cooling rate was high leading to an increase in the rate of nucleation. As a consequence the grain structure got refined and the mechanical characteristic properties got enhanced. On the other hand, at a high pouring temperature the solidification rate decreased accounting for a columnar grain structure with a decrease in the ultimate tensile strength of the casting. The pouring temperature is thus, established as an important processing parameter.

\subsection{Pre-heating and cooling of the mould}

Control of the freezing pattern of the mould housing the melt, decides the size, shape and orientation of the grains and the degree of true metallic continuity of the casting. The nature of freezing of the casting can be varied by heating the mould prior to metal pouring. Also, by selecting the mould material with different thermal properties and employing external cooling arrangements, the rate of dissipation of heat from the mould to the ambience can be varied. Such variations are bound to decide the casting characteristics in terms of the cast structure developed and its soundness including segregation/distribution of the reinforcement phase in the centrifugal casting.

\subsubsection{Mould pre-heating and characteristics of centrifugal casting produced}

The predicted grain-structure of the solidified centrifugal casting, in relation to the pre-heat temperature of the mould, is presented in Figure 6 [35]. This is obtained adopting a classical cellular automation technique [36], using Al-1.0 mass\% Si alloy at a constant mould rotational speed and pouring temperature at various mould temperature. As seen in Figure 6c, at constant melt temperature and mould rotational speed, the secondary columnar grains become broader and prominent when the mould preheat temperature is increased. Also, under these conditions the equiaxed grains become finer. However, when the mould is heated to a relatively lower temperature, the rate of cooling of the mould is increased, more nuclei are generated and the viscosity of the melt is also increased restricting the transport of nuclei in the melt. At the enhanced cooling rate, extended extents of undercooling are induced and large proportions of the generated nuclei, become stable. There is mutual impingement of the large amount of nuclei generated, with their neighboring counterparts during the course of their growth with the concurrent growth restrictions (Fig. 6b). As a consequence of the above, the grains are not free to grow. The columnar grains becomes restricted and grain refinement is encouraged. Here, the rate of nucleation takes over the rate of growth. Thus, as 
predicted, at low mould pre-heat temperature, a resultant fine grain structure is obtained (Fig. 6a).

The above mentioned predicted solidification grain structure, at various mould temperatures pertaining to Al-1.0mass\% Si alloy, is well supported by the experimental work done by Feng et al. [99] concerning centrifugal casting of $\mathrm{Ti}$ based (Ti-6Al-4V) alloy extensively used in the aeronautical and aerospace engineering [100]. Mould preheat temperatures of $673 \mathrm{~K}, 773 \mathrm{~K}$ and $873 \mathrm{~K}$ were adopted for casting of thin walled, vertical cylinders of the alloy with two different wall thicknesses. In order to improve the quality of the castings by closing the porosities/ cavities in the castings, these were pressed under hot isotropic pressure conditions (HIP). The as cast and HIPed microstructure were compared. It was observed that the higher cooling rates generated at lower pre-heat temperatures of the mould, produced a much finer grain structure. At a higher pre-heat temperature of the mould, however, the solidification rate decreased and the number of porosities decreased dramatically. In this case the grain structure was coarsened and the soundness of the cast product was improved. Though, the coarse grain structure could decrease the strength properties of the casting, the investigators [99] observed, the effect attributed to the coarsening of the grain stricture was only secondary to the positive effects of elimination of the cast-pores. For the post HIPed samples cast at a high mould pre-heat temperature, the hot isotropic pressure tended to coarsen the microstructure under the influence of the prevailing high pressure and temperature conditions. The coarsened microstructure imparted a decreasing tendency to the strength and ductility properties of the casting. It was also noted that the overall grain size in the thicker section of the casting was larger in comparison to the thinner section, which could set up a comparatively higher cooling rate. However, under these conditions higher extents of cast pores could be evidenced in the thinner section. This was because, the enhanced rate of cooling of the thinner sections resulted in a faster solidification rate not allowing the completion of expulsion of gases from within the casting. The post HIPed samples for the lower mould pre-heat temperature castings showed smaller extents of micro pores due to the HIPping processing. The tensile properties and ductility of these samples got enhanced.

The mould pre-heat temperature, thus, can decide the extent of refinement of the grain structure of the casting. A decrease in the grain size exhibits an increasing tendency of strength properties of the casting [101-103]. In the instant case, the investigators [99] report that an increase in the mould pre-heat temperature $(673-873 \mathrm{~K})$ resulted in a decrease in the microhardness of the casting. Also the increase in the mould pre-heat temperature increased the fracture toughness and fatigue crack growth (FCG) resistance of the centrifugal casting.

\subsubsection{Mould cooling rate and the centrifugal casting characteristics}

Use of different mould materials based on their thermal properties and the adopted cooling systems for the cooling of the mould in conjunction with pre-heating of the mould to different temperatures, for alterations in the temperature distribution and rate of cooling of the centrifugal casting, have been investigated by many investigators [25,95,104-106]. Such alterations, it is claimed, can bring in improvements in high temperature strength [107] and wear resistance in Al matrix composites [106,107] by manipulating the distribution of reinforcement particles and alterations in the microstructure of the matrix. Investigations conducted by Huang et al. [95], is an example of the above. The investigators fabricated aluminium cast pistons with $\mathrm{SiC}$ particles reinforcement and reported that an increased mould pre-heat temperature enhanced the segregation of hard $\mathrm{SiC}$ particles imparting good wear resistance to the casting surface. The low viscosity of the melt at the prevailing high temperature accounted for greater motion of the dense $\mathrm{SiC}$ particles, assisting such segregations. Luan et al. [25] employed moulds made up of different materials with different thermal properties heated to different pre-heat temperatures to enhance the temperature gradient of the solidifying casting. The solidification rate is directly proportional to the temperature gradient and undercooling in the melt. The investigators [25] claim, by decreasing the mould pre-heat temperature (at a given super heat of the melt) the undercooling was increased, the temperature gradient was stiffened and the solidification rate could be increased. This resulted in a finer grain structure improving the mechanical characteristics of the casting, such as its wear resistance and thermal fatigue properties. An example of the altering cooling rate by the use of specific mould material and the cooling arrangement adopted, can be seen in the experimental work of Zhang et al. [108], while casting of Al-Mg2Si alloy tubes in the centrifugal casting route. Clearly, at high cooling rates (copper mould and water cooling) the grain structure was much refined compared to a relatively low cooling rate (graphite mould). The effects of cooling rate have been presented in Figure 7. The findings of Halvee et al. [109] investigating with Tin, Bronzes and the C92200 alloy cast in the centrifugal casting route are also in line with the reports of Zhang et al. [108].

\section{Illation}

The process parameters involved with fabrication of castings in the rotating mould include the rotational velocity of the mould, the temperature of the mould prior to pouring, the temperature of pouring, the mould material, the mould cooling system and the alloy constituents of the melt. Consistent, continued efforts are on to establish relationships between macro-structural morphology and the different casting parameters. Despite the above, impacts of the casting parameters on solidification pattern and the associated considerations based on qualitative as well as quantitative assessment have not been fully ascertained. Attempts at designing of optimum casting parameters concerning centrifugal casting for obtaining a specified microstructure and an advantageous segregation pattern, keeping the end-use in mind, have not been fully successful. Yet, based on the findings of several investigations, techniques of casting in a rotating mould 


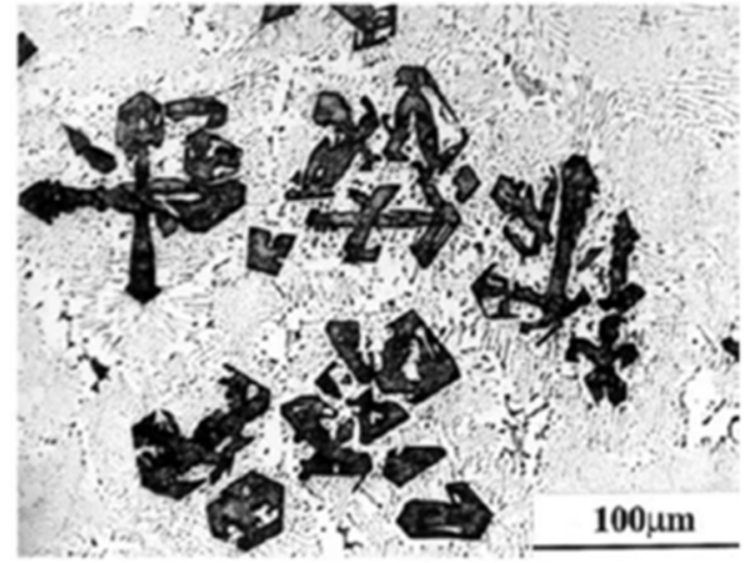

(a)

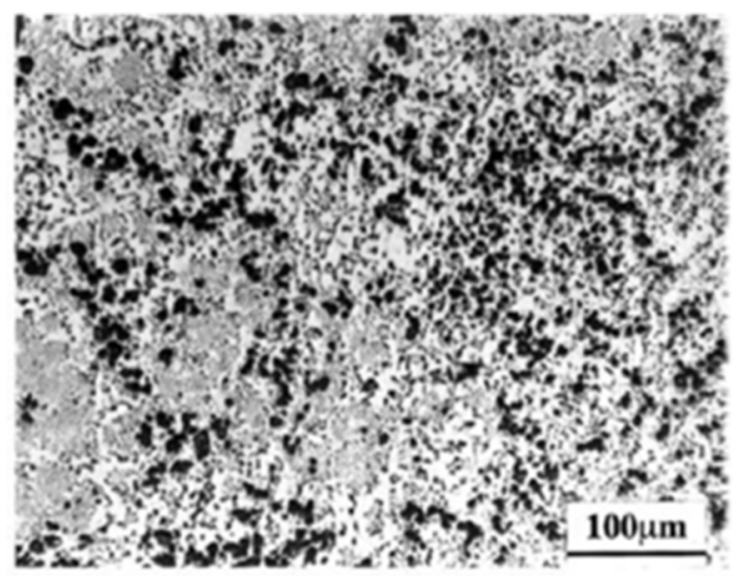

(b)

Fig. 7. Microstructures in outer surfaces of Al-15Mg2Si alloy tubes obtained by using: (a) graphite mould; and (b) copper mould with water cooling [108].

have been adopted successfully for the fabrication of articles for use in different fields of applications. It is indeed claimed that the centrifugal casting can be tailored to meet specific necessities by the control of different casting parameters.

The rotational speed of the mould should be optimum/ critical to ensure that all of the liquid metal fed into the mould, is lifted and held tightly on the inside mould surface. The critical speed is a function of the mould dimensions, volume and viscosity of the melt including the composition of the liquid metal. A casting with poor irregular inside surface results below the critical speed of rotation of the mould on account of the instability in the liquid metal. Similarly, if the speed of rotation is above the critical speed of the mould, imperfections are witnessed in the casting with development of hot tears on its surface. Therefore, adoption of the optimum speed of rotation is advisable. The casting, in this case, exhibits good mechanical properties and lessened wear rate. It may, however, be noted that tubes with low wall thicknesses involving a low volume of the melt, must be processed at a relatively high speed of rotation for good inner surface finish and for obtaining an uniform wall thickness. An increased rotational speed enhances grain refinement by installing a higher solidification rate, while a low rotational speed induces instability, creates vibrations in the melt and may result in the detachment of the tips of the dendrules, again initiating a process of grain refinement. The revolution of the mould is also responsible for distribution of the second phase, inclusions etc., in the solidifying melt. Thus, for a specific end use the microstructure and the macro segregation can be tailored by adopting a suitable mould rotational speed along with other processing factors such as the mould material, alloy constituents of the melt, melt-pouring temperature and the resultant thermal gradient, etc. However, it is necessary to conduct further studies for any concrete opinion on the above.

A casting produced in a rotating mould is often characterized by a banded microstructure which is closely in association with both, the process of segregation of the alloying elements and the impurity atoms held in the melt. The structure consists of concentric zones of dissimilar micro structure which is a structural irregularity known as Banding. Banding, however, is not witnessed in small castings involving lower centrifugal forces. The pattern of segregation depends on the mode of freezing. All of the processing factors as also the rpm of the mould have a say on the mode of freezing, thus contributing to the pattern of segregation. Macro segregation is prompted by the relative motion between the solid and the liquid phases in the mushy zone and rejected solute atoms at the solidification interface. The physical displacement of the phases may be initiated by the liquid movement in the solid/liquid zone on account of thermal variations, solidification shrinkages and density variations in the inter dendritic zone in the solidifying melt. Macro segregation can be normal or inverse and occurs either in the equiaxed grains or in a columnar structure pertaining to the two cases respectively.

The mechanical properties of a casting are upgraded with grain refinement. The grain size and pouring temperature of the liquid metal, are intimately co-related. A lower pouring temperature produces a smaller grain size and reduced dendritic arm spacing (DAS) by enhancing the chilling effect. On the other hand, with the adoption of a higher pouring temperature the solidification time gets elongated permitting the nuclei to grow over a longer period, encouraging a coarse, columnar grain structure. The pouring and mould temperatures along with the ' $\mathrm{G}$ ' factor that depends on the rpm of the rotating mould, decide the graded distribution of the reinforcement particles in the FGMs. It is obvious that at high temperatures, the viscosity of the melt is lowered and the solidification rate is lowered. This assists the ease and prolonged movement of the reinforcement particles in the melt. Thus, stronger graded distribution is prompted when the pouring temperature is increased. The pouring temperature also decides the cooling rate of the casting. 
Along with the mould temperature, the system adopted for mould cooling also decides the grain structure including the associated mechanical properties of the casting.

Control of freezing pattern of the casting decides the end use of the casting by dictating the structure and soundness of the casting. It is worth mentioning, the pouring rate, the pouring temperature, mould material, mould temperature and the mould cooling system can all be appropriately selected to control the freezing pattern. As a consequence, the second phase particles undergo desired graded distribution and considerable refinement of the grain structure can also be made possible.

The above would reflect the importance of investigations conducted pertaining to the process of casting in a rotating mould. Attempts have been made extensively to characterize the centrifugal casting process in terms of the processing parameters and to correlate these with the characteristic properties concerning the casting. The results are encouraging and many queries regarding the mechanical characteristic properties of the casting obtained adopting the centrifugal casting route have been adequately answered. However, there still exists a lot to be understood. For example, adequate mention is not available in the literature concerning the intricacies of the solidification structure developed in castings produced in a rotating mould and the impact of the same on the characteristics of the casting. Literature also does not provide sufficient information highlighting the different types of fluid flows as applied to the motion of the melt in a rotating mould and the associated property developments in the real life case. Although, the unfailing, definite impact of the casting variables on the solidification morphology cannot be denied at any level, there exists a lack of clear understanding, as on date, concerning the same, pertaining to the effect of these variables on the cast-structure developed which influence its characteristic mechanical properties. Thus, it has not been possible to design the casting conditions pertaining to centrifugal casting such that the desired uniform structure that reflects the characteristic properties of the casting, is obtained. Though, computer simulation techniques are used to carefully deal with a large number of process parameters simultaneously, experimenters are still not able to strike a fully acceptable correlation between the simulated and the real-life case. Despite the above, the versatility of casting in a rotating mould that affects the cast structure and soundness, the segregation pattern, specifically the gradation of the reinforcement particle distribution in the melt, paves a way for a considered application of the method in various fields.

\section{Research gap}

A careful insight would reveal, much effort has been made by several researchers to throw light on various aspects of casting in a rotating mould. Yet, many of the intricacies of the process including its specific participation concerning property enhancement of the product have not been exploited by the researchers at length. The reasons for the same may be many, but for a detailed analysis of the process and its specific utility in the manufacturing industry, it is most desirable that efforts must be initiated to answer to the following research gap:

- General rules have to be formulated to reflect the effect of rotational speed of the mould on the cast structure which will enable one to analyze the mechanical performance of the casting.

- In this respect due considerations must be given to the factors which are, in general, not considered by the researchers. These include 'mould vibration', 'lowering of the thermal gradient with lapse of time in the liquid metal', 'fragmentation of the tip of the dendrites during solidification' etc. These factors would govern the final structure of the casting and through light on the detailed cast structure such as the extent of equiaxed structure, columnar grains etc.

- The types of fluid flow in a rotating mould have not been studied as it is a cumbersome process. Due considerations must be attached to this aspect since fluid flow in the rotating mould decides the structural and property development aspects in the centrifugal casting.

- Appropriate, accurate and sufficient computer simulation techniques must be developed to analyse the centrifugal casting process. This would help one to establish an acceptable correlation between the simulated case and real life case.

This research did not receive any specific grant from funding agencies in the public, commercial, or not-for-profit sectors.

\section{References}

1. R. Rodriguez-Castro, Processing, Microstructure and Mechanics of Functionally Graded Al A359/SiCp Composite, Ph.D. Thesis, State University of New York at Buffalo, 2000, p. 195

2. A. Velhinho, P.D. Sequeira, F.M. Braz Fernandes et al., Al/ SiCp Functionally graded metal-matrix composites produced by centrifugal casting: effect of particle grain size on reinforcement distribution, Mater. Sci. Forum 423-425 (2003) 257-262

3. T.P.D. Rajan, DR.M. Pillai, B.C. Pai, Centrifugal casting of functionally graded aluminium matrix composite components, Int. J. Cast Metals Res. 21 (2008) 1-4

4. T.P.D. Rajan, DR.M. Pillai, B.C. Pai, Centrifugal casting: a potential technique for making functionally graded materials and engineering components, Indian Foundry J. 53 (2007) 79-87

5. W. Kai, J. Tao, H. Zhili et al., Mechanical and thermal expansion properties of $\mathrm{SiCp} / \mathrm{ZAlSi9Mg}$ composites produced by centrifugal casting, J. Wuhan Univ. Technol. Mater. Sci. Ed. (2016)

6. M.J. Li, Y.C. Wu, F.S. Yen et al., Influence of ionic mobility on the phase transformation route in $\mathrm{Y}_{3} \mathrm{Al}_{5} \mathrm{O}_{12}$ (YAG) stoichiometry, J. Eur. Ceram. Soc. 31 (2011) 2099-2106

7. M. Poornesh, N. Harish, K. Aithal, Mechanical and tribological properties of centrifugally cast Al-Si-SiC composites, Am. J. Mater. Sci. 6 (2016) 31-35

8. O. Savas, R. Kayicki, F. Ficici, Production of functionally graded $\mathrm{SiC} / \mathrm{Al}-\mathrm{Cu}-\mathrm{Mg}$ composite by centrifugal casting, Sci. Eng. Compos. Mater. 21 (2014) 1-5 
9. X.H. Qin, W.X. Han, C.G. Fan et al., Research on distribution of $\mathrm{SiC}$ particles in aluminum-alloy matrix functionally graded composite tube manufactured by centrifugal casting, J. Mater. Sci. Lett. 21 (2002) 665-667

10. R. Rodriguez-Castro, M.H. Kelestemur. Processing and microstructural characterization of functionally gradient $\mathrm{Al}$ A359/SiCp composite, J. Mater. Sci. 37 (2002) 1813-1821

11. R.S. Vikas, M.U. Maiya, E. Jayakumar et al., Processing and characterization of $\mathrm{SiCp}$ reinforced functionally graded AA 6061 aluminium metal matrix composites, Int. J. Adv. Mech. Aeronaut. Eng. 1 (2014) 61-65

12. E. Jayakumar, J.C. Jacob, T. Rajan et al., Processing and characterization of functionally graded aluminum (A319)SiCp metallic composites by centrifugal casting technique, Metall. Mater. Trans. 47 (2016) 4306-4315

13. A. Velhinho, J.D. Botas, E. Ariza et al., Tribocorrosion studies in centrifugally cast Al-matrix SiCp-reinforced functionally graded composites, Mater. Sci. Forum 455-456 (2004) 871-875

14. K. Wang, J. Cheng, W. Sun et al., An approach for increase of reinforcement content in particle rich zone of centrifugally cast $\mathrm{SiCP} / \mathrm{Al}$ composites, J. Compos. Mater. 46 (2011) 1021-1027

15. X. Yong, L. Changming, Z. Yanbo et al., Centrifugal casting processes of manufacturing in situ functionally gradient composite materials of Al-19Si-5Mg alloy, Rare Metals $\mathbf{2 8}$ (2009) 405-411

16. N. Radhika, R. Raghu, Development of functionally graded aluminium composites using centrifugal casting and influence of reinforcements on mechanical and wear properties, Trans. Nonferrous Met. Soc. China 26 (2016) 905-916

17. M.F. Forster, R.W. Hamilton, R.J. Dashwood et al., Centrifugal casting of aluminium containing in situ formed TiB2, Mater. Sci. Technol. 19 (2003) 1215-1219

18. S. Kumar, V. Subramaniya Sarma, B.S. Murty, Functionally graded $\mathrm{Al}$ alloy matrix in-situ composites, Metall. Mater. Trans. A 41 (2009) 242-254

19. N. Radhika, R. Raghu, Three body abrasion wear behaviour of functionally graded aluminium/B4C metal matrix composite using design of experiments, Proc. Eng. 97 (2014) 713-722

20. N.B. Duque, Z. Humberto Melgarejo, O. Marcelo Suarez, Functionally graded aluminum matrix composites produced by centrifugal casting, Mater. Character. 55 (2005) 167-171

21. J.R. Davis, Corrosion of aluminum and aluminum alloys, ASM International, Materials Park, OH7, 1999, p. 180

22. J. Yupa, Corrosion behavior of $\mathrm{Al}-\mathrm{Cu}-\mathrm{B}$ composites in $3.5 \%$ $\mathrm{NaCl}$ solution, MS. Thesis, The University of Puerto Rico, Mayaguez, USA, 2004

23. F. Erdemir, A. Canakci, T. Varol, S. Ozkaya, Corrosion and wear behavior of functionally graded $\mathrm{Al} 2024 / \mathrm{SiC}$ composites produced by hot pressing and consolidation, J. Alloy Compd. 644 (2015) 589-596

24. F. Erdemir, A. Canakci, T. Varol, Microstructural characterization and mechanical properties of functionally graded $\mathrm{Al} 2024 / \mathrm{SiC}$ composites prepared by powder metallurgy techniques, Trans. Nonferrous Metals Soc. China 25 (2015) 3569-3577

25. Y. Luan, N. Song, Y. Bai et al., Effect of solidification rate on the morphology and distribution of eutectic carbides in centrifugal casting high-speed steel rolls, J. Mater. Process. Technol. 210 (2010) 536-541
26. L. Niu, Y. Xu, X. Wang, Fabrication of WC/Fe composite coating by centrifugal casting plus in-situ synthesis techniques, Surf. Coat. Technol. 205 (2010) 551-556

27. M. Kaan Pehlivanoglu, M. Vedat Akdeniz, A. Sakir Bor, Structural characterization of iron-based bulk metallic glass alloys produced by centrifugal casting, Chem. Eng. Commun. 190 (2003) 925-935

28. C.G. Kuo, C.G. Chao, A novel method of centrifugal processing for the synthesis of lead-bismuth eutectic alloy nanospheres and nanowires, Int. J. Adv. Manuf. Technol. 32 (2007) 468-472

29. C.K. Kim, K.H. Kim, J.M. Park et al., Development of advanced research reactor fuels using centrifugal atomization technology, Metals Mater. 5 (1999) 149-156

30. K.H. Kim, D.B. Lee, C.K. Kim et al., Characteristics of U3Si and U3Si2 powders prepared by centrifugal atomization, J. Nucl. Sci. Technol. 34 (1997) 1127-1132

31. A.B. Shuck, The development of equipment and methods for centrifugally casting reactor fuel slugs, United States (1953). Web doi: $10.2172 / 4374631$

32. O. Odawara, Ceramic linings of pipes using SHS technology, Key Eng. Mater. 122-124 (1996) 463-478

33. W. Xi, S. Yin, S. Guo et al., Stainless steel lined composite steel pipe prepared by centrifugal-SHS process, J. Mater. Sci. 35 (2000) 45-48

34. W. Huisman, T. Graule, L.J. Gauckler, Centrifugal slip casting of zirconia (TZP), J. Eur. Ceramic Soc. 13 (1994) 33-39

35. S.R. Chang, J.M. Kim, C.P. Hong, Numerical simulation of microstructure evolution of $\mathrm{Al}$ alloys in centrifugal casting, ISIJ Int. 41 (2001) 738-747

36. M.F. Zhu, C.P. Hong, A modified cellular automaton model for the simulation of dendritic growth in solidification of alloys, ISIJ Int. 41 (2001) 436-445

37. K.S. Keerthiprasad, M.S. Murali, P.G. Mukunda et al., Numerical Simulation and Cold Modeling experiments on centrifugal casting, Metal. Mater. Trans. B 42B (2011) $144-155$

38. Y. Waranabe, H. Eryu, K. Matsuura, Evaluation of threedimensional orientation of $\mathrm{Al}_{3} \mathrm{Ti}$ platelet in Al-based functionally graded materials fabricated by a centrifugal casting technique, Acta Mater. 49 (2001) 775-783

39. S. Sarkar, A.K. Lohar, S.C. Panigrahi, Vertical centrifugal casting of aluminum matrix particle reinforced composites, J. Reinforced Plast. Compos. 28 (2008) 1013-1020

40. W. Shi-ping, L. Chang-yun, U. Jing-jie, S. Yan-qing, L. Xiuqiao, U. Heng-zhi, Numerical simulation and experimental investigation of two filling methods in vertical centrifugal casting, Trans. Nonferrous Met. Soc. China 16 (2006) 1035-1040

41. F. Li, D. Wang, Y. Jiang, L. Yang, Y. Zhao, X. Zhang, Effect of centrifugal casting process on mold filling and grain structure of K418B turbine guide, Int. J. Adv. Manuf. Technol. 104 (2019) 3065-3072

42. M.P. Gopal, S.R. Sasihitlu, K.A. Subbanna et al., An understanding of fluid behaviour in centrifugal casting, AFI/TFI-2007, Commemoration of the 100th Anniversary of Tohoku University, December 14-15, 2007, Sendai, Miyagi, Japan.

43. S.K. Wilson, R. Hunt, B.R. Duffy, On the critical solutions in coating and rimming flow on a uniformly rotating horizontal cylinder, J. Mech. Appl. Math. 55 (2002) 357-383 
44. J.M. Lopez, F. Marques, A.H. Hirsa et al., Symmetry breaking in free surface cylinder flows, J. Fluid Mech. 502 (2004) 99-126

45. F. Marques, A.H. Hirsa, R. Miraghaie, Symmetry breaking in free-surface cylinder flows, J. Fluid. Mech. 502 (2004) 99-126

46. R.A. Shailesh, P.G. Mukunda, S.R. Shrikantha, Experimental studies of flow patterns of different fluids in a partially filled rotating cylinder, J. Appl. Fluid. Mech. 2 (2009) 39-43

47. R.A. Shailesh, P.G. Mukunda, S.R. Shrikantha, AFI TFI-2007, Commemoration of the 100th Anniversary of Tohoku University, Sendai, Miyagi, Japan, 2007

48. P.G. Mukunda, S. Rao, S.S. Rao, Influence of rotational speed of centrifugal casting process on appearance, microstructure, and sliding wear behaviour of Al-2Si cast alloy, Met. Mater. Int. 16 (2010) 137-143

49. P.G. Mukunda, S. Rao, S.S. Rao, Inference of optimal speed for sound centrifugal casting of Tin, Can. Metal. Quart. 48 (2009) 157-165

50. R.A. Shailesh, M.S. Tattimani, S.S. Rao, Understanding melt flow behavior for Al-Si alloys processed through vertical centrifugal casting, Mater. Manufactur Process. 30 (2015) $1305-1311$

51. A.S. Rao, M.S. Tattimani, S.S. Rao, Effect of rotational speeds on the cast tube during vertical centrifugal casting process on appearance, microstructure, and hardness behavior for Al-2Si alloy, Metal. Mater. Trans. B 46B (2015) 793-799

52. J.W. Park, H.J. Kim, Melt filling behaviors and primary si particle distribution on horizontal centrifugal casting in b390 aluminum alloy, Int. J. Metal Casting 11 (2016) 802-811

53. S.Y. Lee, S.M. Lee, C.P. Hong, Numerical modeling of deflected columnar dendritic grains solidified in a flowing melt and its experimental verification, ISIJ Int. 40 (2000) $48-57$

54. L.P. Wang, D.R. Liu, E.J. Guo, Modeling of 'banding' microstructure formation in centrifugally solidified ti-6al-4v alloy, Acta Metall. Sin. 21 (2008) 399-408

55. J.W. Yeh, S.H. Jong, The cast structure of a 7075 alloy produced by a water-cooling centrifugal casting method, Metal. Mater. Trans. A 25 (1994) 643-650

56. C.G. Kang, P.K. Rohatgi, Transient thermal analysis of solidification in a centrifugal casting for composite materials containing particle segregation, Metall. Mater. Trans. B 27 (1996) 277-285

57. Q.M. Liu, Y.N. Jiao, Y.S. Yang, Z.Q. Hu, Theoretical analysis of the particle gradient distribution in centrifugal field during solidification, Metall. Mater. Trans. B 27 (1996) $1025-1029$

58. R. Nadella, D.G. Eskin, Q. Du, L. Katgerman, Macrosegregation in direct-chill casting of aluminum alloys, Prog. Mater. Sci. 53 (2008) 421-480

59. Q. Du, D.G. Eskin, L. Katgerman, Modelling macrosegregation during DC casting of multi-component aluminum alloys, Metall. Mater. Trans. A 38A (2007) 180-186

60. D.G. Eskin, L. Katgerman, Macrosegregation mechanisms in direct-chill casting of aluminium alloys, Mater. Sci. Forum 630 (2009) 193-199
61. Y. Watanabe, H. Sato, Review fabrication of functionally graded materials under a centrifugal force, Nanocompos. Unique Prop. Appl. Med. Ind. (2011). doi:10.5772/20988

62. Y. Fukui, K. Takashima, C.B. Ponton, Measurement of Young's modulus and internal friction of an in situ $\mathrm{Al}-\mathrm{Al} 3 \mathrm{Ni}$ functionally gradient material, J. Mater. Sci. 29 (1994) $2281-2288$

63. Y. Watanabe, N. Yamanaka, Y.Z. Fukui, Metallkd 88 (1997) 717-721

64. C.N. Wei, H.Y. Bor, C.Y. Ma, T.S. Lee, A study of IN-713LC superalloy grain refinement effects on microstructure and tensile properties, Mater. Chem. Phys. 80 (2003) 89-93

65. P. Shailesh, S. Sundarrajan, M. Komaraiah, Optimization of process parameters of Al-Si alloy by centrifugal casting technique using Taguchi design of experiments, Proc. Mater. Sci. 6 (2014) 812-820

66. R.W. Armstrong, Mater. Res. Soc. Symp. Proc. 362 (1995) 369

67. T.R. Smith, R.W. Armstrong, P.M. Hazzledine et al., Mater. Res. Soc. Symp. Proc. 362 (1995) 31

68. N. Hansen, Polycrystalline strengthening, Metall. Trans. 16 (1985) 2167-2190

69. W. Mangen, E. Nembach, The effect of grain size on the yield strength of the $\gamma /$-hardened superalloy NIMONIC PE16, Acta Metall. 37 (1989) 1451-1463

70. M.R. Bhatti, W.T. Roberts, in Proceedings of the Second International Symposium on Advanced Materials (1991) 90

71. D.A. Chang, R. Nasser-Rafi, S.L. Robertson, in: E.A. Loria (Ed.), The Minerals Metals and Materials Society. Superalloy 718, 625 and Various Derivatives (1991) 271

72. N. Church, P. Wieser, J.F. Wallace, Mod. Castings 49 (1966) 129

73. U.-G. Metals, J.J. Burke, V. Weiss, eds., Syracuse University Press, New York, NY, 1970

74. M.C. Flemings, Solidification Processing, McGraw-Hill, New York, NY, 1974, pp. 34-44

75. Y. Fukui, Fundamental investigation of functionally gradient material manu-facturing system using centrifugal force, JSME Inst. J. Ser. III 34 (1991) 144-148

76. Y. Miyamoto, W.A. Kaysser, B.H. Rabin, A. Kawasaki, R. G. Ford (Eds.), Functionally Graded Materials: Design, Processing and Applications, Kluwer Academic Publishers, Boston, 1999

77. B.M. Zhang, Centrifugal Casting (in Chinese), Machinery Industry Press, Beijing, 2006

78. S. Raghunandan et al., Processing of primary silicon and $\mathrm{Mg} 2 \mathrm{Si}$ reinforced hybrid functionally graded aluminum composites by centrifugal casting, Mater. Sci. Forum $\mathbf{7 1 0}$ (2012) 395-400

79. Y. Fukui, H. Okada, N. Kumazawa et al., Near-net-shape forming of $\mathrm{Al}-\mathrm{Al} 3 \mathrm{Ni}$ functionally graded material over eutectic melting temperature, Metal. Mater. Trans. A 31 (2000) 2627-2636

80. Y. Watanabe, I.S. Kim, Y. Fukui, Microstructures of functionally graded materials fabricated by centrifugal solid-particle andin-situ methods, Metals Mater. Int. 11 (2005) 391-399

81. Y. Watanabe, H. Sato, T. Ogawa, I.S. Kim, Density and hardness gradients of functionally graded material ring fabricated from Al-3 mass $\% \mathrm{Cu}$ alloy by a centrifugal in-situ method, Mater. Trans. 48 (2007) 2945-2952 
82. A. Mehditabar, G.H. Rahimi, S.E. Vahdat, Characterization of $\mathrm{Al}-\mathrm{Al} 2 \mathrm{Cu}$ functionally graded material produced by using horizontal centrifugal casting, Multidiscip. Model. Mater. Struct. (2018) doi:10.1108/mmms-10-2017-0114

83. M.R. Derakhshesh, H. Sina, H. Nazemi, The comparison of the microstructure and hardness of $\mathrm{Al}-\mathrm{B}$ and $\mathrm{Al}-\mathrm{Mg}-\mathrm{B}$ composites, Int. J. Adv. Des. Manufactur. Technol. 4 (2011) $27-31$

84. S. El-Hadad, H. Sato, E. Miura-Fujiwara, Y. Watanabe, Fabrication of $\mathrm{Al}-\mathrm{Al} 3 \mathrm{Ti} / \mathrm{Ti} 3 \mathrm{Al}$ functionally graded materials under a centrifugal force, Materials 3 (2010) 4639-4656

85. S. El Hadad et al., Investigation of the mechanical properties in $\mathrm{Al} / \mathrm{Al} 3 \mathrm{Zr}$ FGMs fabricated by centrifugal casting method, Mater. Sci. Forum 631-632 (2010) 379-384

86. Y. Watanabe, A. Kawamoto, K. Matsuda, Particle size distributions in functionally graded materials faricated by the centrifugal solid-particle method, Compos. Sci. Technol. 62 (2002) 881-888

87. Y. Watanabe, R. Sato, K. Matsuda, Y. Fukui, Evaluation of particle size and particle shape distributions in $\mathrm{Al}-\mathrm{Al} 3 \mathrm{Ni}$ FGMs fabricated by a centrifugal in-situ method, Sci. Eng. Compos. Mater. 11 (2004) 185-199

88. N. Mykura, S. Murphy, In 25th Annual Conference of Metallurgists, 1986 Proceedings International Symposium on Zinc-Aluminium (ZA) Casting Alloys, In: G.B. Lewis, R. J. Barnhurst, C.A. Loon (Eds.), (1986)

89. P. Porot, N. Ventham, R. Jones, J. Spittle, Structural variation in near-eutectic zinc-aluminum alloys, Metallography 20 (1987) 181-197

90. G. Chen, M. Tong, Z. Zhu, Study on the macrosegregation of aluminum in centrifugal-cast ZA27 alloy, Mater. Sci. Eng. A 265 (1999) 306-309

91. F.L. Mondolfo, Aluminium Alloys: Structure and Properties, Butterworth, London and Boston, 1976

92. M.G. Kim, S.K. Kim, Y.J. Kim, Effect of mold material and binder on metal-mold interfacial reaction for investment castings of titanium alloys, Mater. Trans. 43 (2002) $745-750$

93. W.Z. Luo, J. Shen, Z.X. Min et al., Investigation of interfacial reactions between $\mathrm{TiAl}$ alloy and crucible materials during directional solidification process, Rare Metal Mater. Eng. 8 (2009) 031

94. S. Yanwei, F. Kun, C. Cheng et al., Effects of pouring temperature on interfacial reaction between $\mathrm{Ti}-47.5 \mathrm{Al}-2.5 \mathrm{~V}$ $1 \mathrm{Cr}$ alloy and mold during centrifugal casting, J. Wuhan Univ. Technol. Mater. Sci. (2016)
95. X. Huang, C. Liu, X. Lu et al., Aluminum alloy pistons reinforced with $\mathrm{SiC}$ fabricated by centrifugal casting[J], J. Mater. Process. Technol. 211 (2011) 1540-1546

96. Y.W. Sui, B.S. Li, A.H. Liu et al., Physical simulation of infiltration flow during centrifugal casting titanium alloy melts feeding, Rare Metal Mater. Eng. 38 (2009) 1537-1541

97. Z.J. Wang, J.L. Du, J.L. Li et al., Influence of sintering temperature on the structure and high-temperature discharge performance of $\mathrm{LiNi} 1 / 3 \mathrm{Mn} 1 / 3 \mathrm{Co} 1 / 3 \mathrm{O} 2$ cathode materials, J. Wuhan Univ. Technol. Mater. Sci. Ed. 30 (2015) 894-899

98. B. Praveen Kumar, P. Shailesh, S. Sundarrajan, Experimental investigation on centrifugal casting of 5500 alloy: a Taguchi approach, Sci. Res. Essays 7 (2012) 3797-3808

99. X. Feng, J. Qiu, Y. Ma et al., Influence of processing conditions on microstructure and mechanical properties of large thin-wall centrifugal $\mathrm{Ti}-6 \mathrm{Al}-4 \mathrm{~V}$ casting, J. Mater. Sci. Technol. 32 (2016) 362-371

100. R.R. Boyer, An overview on the use of titanium in the aerospace industry, Mater. Sci. Eng. A 213 (1996) 103-114

101. G. Wegmann, J. Albrecht, G. Lutjering et al., Z. Metallk 88 (1997) 764-773

102. G. Lutjering, Influence of processing on microstructure and mechanical properties of $(\alpha+\beta)$ titanium alloys, Mater. Sci. Eng. A 243 (1998) 32-45

103. W.H. Miller, R.T. Chen, E.A. Starke, Microstructure, creep, and tensile deformation in Ti-6Al-2Nb-1Ta-0.8Mo, Metall. Trans. A 18 (1987) 1451-1468

104. S. Wei, The Centrifugal Casting Machine Company, and Steve Lampman, Centrifugal Casting. ASM International ASM Handbook 15 (2008) 667-673

105. X. Lin, C. Liu, H. Xiao, Fabrication of Al-Si-Mg functionally graded materials tube reinforced with in situ $\mathrm{Si} / \mathrm{Mg} 2 \mathrm{Si}$ particles by centrifugal casting, Compos. B 45 (2013) 8-21

106. K. Wang, Z.M. Zhang, T. Yu et al., The transfer behavior in centrifugal casting of $\mathrm{SiCp} / \mathrm{Al}$ composites, J. Mater. Process. Technol. 242 (2017) 60-67

107. S.C. Tjong, Z.Y. Ma, The high-temperature creep behaviour of aluminium-matrix composites reinforced with $\mathrm{SiC}, \mathrm{Al}_{2} \mathrm{O}_{3}$ and $\mathrm{TiB}_{2}$ particles, Compos. Sci. Technol. 57 (1997) 697-702

108. J. Zhang, Z. Fan, Y. Wang, B. Zhou, Hypereutectic aluminium alloy tubes with graded distribution of $\mathrm{Mg} \mathrm{Si}$ particles prepared by centrifugal casting, Mater. Des. 21 (2000) 149-153

109. A. Halvaee, A. Talebi, Effect of process variables on microstructure and segregation in centrifugal casting of C92200 alloy, J. Mater. Process. Technol. 118 (2001) 123-127 